Motrivivência $\quad$ v. 26 , n. 42, p. 263-280, junho/2014

http://dx.doi.org/10.5007/2175-8042.2014v26n42p263

\title{
JOGO, ESPORTE, CRIANÇA E ENSINO: aproximações com a Psicologia Social de Mead
}

Carlos Luiz Cardoso

\section{RESUMO}

O artigo reflete o jogo e o esporte no interior da psicologia social do filósofo G. H. Mead, como orientação para a Educação Física escolar. Inicialmente indica os princípios do 'condutismo social' [sociedade, pessoa e mente]. Em seguida mostra a 'emergência' do 'outro generalizado' na passagem do jogo ao esporte. Mais adiante destaca o 'movimento renovador' da década de 80 e algumas referências para o ensino no Brasil. Finalmente reflete a necessidade de compreender o desenvolvimento do self na educação escolar, destacando as concepções 'críticas' para a formação didática dos professores.

Palavras-chave: Psicologia Social; Educação Física; Jogo e Esporte; Criança e Self. 


\section{INTRODUÇÃO}

A Educação Física escolar brasileira poderia não só ter se aproximado da obra de George Herbert Mead para melhor compreender a abordagem referente à relação 'indivíduo e sociedade' e por consequência a visão psicossocial do jogo e do esporte como também ter se aprofundado na reflexão sobre a construção do 'outro generalizado' no do currículo escolar, considerando a passagem de gestos indicativos para condutas sociais. Nosso campo de intervenção e investigação carece de aprofundamentos em aspectos psicológicos e sociológicos vinculados a outras concepções, principalmente pelo fato de terem sido originadas no interior da academia e oferecer possibilidades de perceber a conduta do ser humano/da pessoa, não a partir de bases comportamentalistas individualizadas (behaviorismo), mas sim a partir das condutas sociais (behaviorismo social), conforme preconizou nosso autor em questão.

Mead (1972) indicou a possibilidade dessa nova compreensão, no entanto a dificuldade continua. Seria mais por resistência em 'mudar' do que a falta de 'ajuda'?

Questões didático-pedagógicas têm sido estudadas a partir de muitos campos de conhecimento. A psicologia do esporte e a Educação Física escolar carecem de fundamentos tanto sócio-psicológicos como psicossociológicos de diferentes matizes. Mead sugere uma vertente que não tem como origem o indivíduo nem a sociedade, mas a relação dialética entre 'o indivíduo e a sociedade', por meio de um terceiro componente de equilíbrio e passagem, que é a personalidade, o 'self', , precedido pela construção do 'outro generalizado'.

A utilização dessa contribuição no campo da Educação Física pode ser considerada superficial. Seu pensamento em relação ao jogo e ao esporte não é muito conhecido na academia entre os pesquisadores da área. Todavia, em outros campos de investigação como a Psicologia, com a gênese do 'eu' de Piaget, juntamente com a gênese do 'self' de Mead, tem servido de base para o filósofo alemão Jürgen Habermas. Ele é pertencente à segunda geração da Escola de Frankfurt, e tem como fundamentos de sua teoria da 'ação comunicativa' a virada paradigmática - da consciência à linguagem - baseada, por um lado em Mead, e por outro em Durkheim.

Mais recentemente, com o surgimento e direção de Axel Honneth na Escola de Frankfurt, pertencente agora à chamada terceira geração de pensadores dessa escola, percebe-se um resgate do psicólogo e filósofo norte-americano Mead, bem como do psicólogo inglês Winnicott e do filósofo alemão Hegel. As bases de suas reflexões críticas sobre a sociedade referem-se ao déficit teórico deixado por Habermas quanto aos 'movimentos sociais'. Werle (2010) destaca que esse retorno da tradição frankfurteana a pensadores originais garante o vínculo e a continuidade da Teoria Crítica da Sociedade iniciada no início do século passado.

Um exercício de exploração e clareamento de ideias e concepções que fazem parte da obra de Mead permite que sejam compreendidas, a partir de suas orientações didático-pedagógicas, alguns elementos básicos sobre jogo e esporte. Portanto, esse ensaio procura contribuir com o campo da Educação Física escolar brasileira naquilo que diz respeito aos conteúdos mais populares no ambiente educacional - esporte.

Segundo Bracht (1999a), o 'movimento renovador' do campo educacional da Educação Física brasileira, originado 
nos anos 80 do século passado influenciou o surgimento de vertentes e abordagens metodológicas críticas denominadas:

a) concepção de 'aulas abertas às experiências';

b) concepção 'crítico-emancipatória'; e

c) concepção 'crítico-superadora'.

Tais concepções são fundamentadas em orientações crítico-hermenêuticas e crítico-dialéticas, o que permite manter o vínculo com o mundo das relações sociais do 'indivíduo e sociedade' e da relação 'pessoa e papéis sociais', necessários na ligação entre educação/formação, jogo/ esporte e indivíduo/sociedade.

Para manter a criticidade da nossa abordagem exploratória, estabelecemos dois objetivos fundamentais:

1) Destacar as unidades significativas da Psicologia Social de Mead no interior das concepções de jogo e esporte inserindo-as na reflexão sobre metodologias de ensino esportivo e concepções dos processos de ensino e de aprendizagem escolar nas propostas 'críticas' da Educação Física escolar brasileira; e

2) Identificar os fundamentos didático-pedagógicos do 'behaviorismo social/ condutismo social' de Mead, considerando os elementos sócio-psicológicos da vertente interacionista.

Destaca-se também algumas questões norteadoras para reflexão:

a) qual a relação de Mead com a educação, o jogo e o esporte?

b) a Educação Física escolar brasileira pode se apoiar nas concepções de Mead e seus colaboradores para a compreensão de problemas didático-pedagógicos?

\section{A psicologia social de Mead}

\subsection{O 'condutismo social'}

Mead (apud Haguette, 1987) não publicou uma obra completa e sistemática. Tudo foi coletado através de anotações das suas palestras, aulas e conferências. A mais completa foi organizada por Charles Morris, em 1934, com o título 'Mind, Self and Society'. Desenvolve suas ideias sobre a relação dialética entre o indivíduo e a sociedade, através de algo que ele vai chamar de 'self' (personalidade). Esse passa a ser o veículo de relação entre as duas extremidades da realidade e ao mesmo tempo esse processo vai se constituindo na gênese do 'self', o que vai permitir o desenvolvimento de símbolos significantes, por um lado pelas redes de significações sociais e por outro pelo processo de comportamento da mente.

Toda a obra de Mead possui uma orientação filosófica pragmática, preocupado mais em mostrar como esse processo acontece na vida cotidiana e por isso, então, passou a ser chamado de 'arquiteto'. Denominou, inicialmente, sua teoria de 'behaviorismo social', até porque era uma resposta aos pesquisadores do comportamento humano, que partiam dos aspectos psíquicos e não sociais para explicar o comportamento humano (chamados behavioristas radicais como J. B. Watson - movimento existente na psicologia de característica eminentemente norte-americana).

Para Mead, todo comportamento humano é descritível e é um ato social não só como um comportamento com origens 'externas', mas também um comportamento com 'significados encobertos'. Não é possível admitir o comportamento humano elaborado a partir de mecanismos do nível de infra-humanos como nos animais, mas 
concebê-lo através de uma instintiva investigação compreensiva.

A partir daí, Mead passa a indicar que o comportamento humano tem uma precedência social sobre o 'self' e mais tarde começará a fazer parte da mente. Essa ordem inclusive é contrária à sequência apresentada em seu livro, no entanto não altera nem o conteúdo nem a lógica da sua teoria. Para uma melhor compreensão, vamos acompanhar a sequência prevista por Mead (da sociedade, pela personalidade até a mente).

\subsection{Sociedade}

Para o nosso autor em questão toda a atividade grupal se baseia em um comportamento cooperativo. Mesmo em sociedades infra-humanas existe o aspecto cooperativo, embora de características somente fisiológica, pois seus padrões de associação nunca se alteram. Ficam sempre naquele nível no qual conhecemos. Mesmo ao longo de várias gerações as formigas continuam a se associar daquela forma. Já por outro lado, a cooperação humana apresenta certa diversidade nos padrões, não só de origem fisiológica, mas sim a partir daquilo que Mead (apud Haguette, 1987) indica:

a) quando um indivíduo percebe a 'intenção' dos atos de outro indivíduo,

b) então ele constrói sua própria resposta baseado naquela intenção.

Esse processo vai exigir que a cooperação entre os seres humanos apresente alguns mecanismos a partir de cada ator individualmente:

a) que ele possa entender as linhas de ação dos outros e,

b) que ele possa direcionar seu próprio comportamento a fim de acomodar-se àquelas linhas de ação.

O comportamento humano não é uma resposta direta e automatizada (mecânica) em direção às atividades dos outros. Antes ela passa por responder às 'intenções' das atividades dos outros. É a resposta a um futuro e intencional comportamento que os outros irão perceber e não somente uma resposta para o presente imediato. Todas as intenções, neste momento, são transmitidas por meio de gestos que tornam-se simbólicos, porque poderão ser interpretados a qualquer momento. Por meio da fala, ganham sentido e são então interpretados como 'símbolos significantes'.

O componente mais significativo de um ato, ou seja, de uma atividade mental, acontece através da possibilidade de 'assumir o papel do outro', colocando-se na posição do outro e identificando-se com ela. Mead vai chamar de 'outro generalizado', pois o indivíduo cria em seu interior níveis complexos de consciência, saindo de si mesmo indo até outras pessoas (através da criação do 'self'. Ela não vem 'a priori', ela é construída socialmente). Toda essa criação da transferência/passagem de si para o outro é permitida pela conversação de gestos ${ }^{2}$.

Essa relação entre os indivíduos surge da habilidade de responder a seus

2 Mead (1986) vai apresentar essa mudança de nível quando descreve a criança que joga/brinca e que num determinado momento seguinte começa a participar do esporte. Passa, então, de um nível de exigência menor (jogo) para um nível mais complexo e organizado (esporte). 
próprios gestos. O indivíduo começa respondendo para si mesmo chegando até um momento em que passa a responder também aos outros. Por isso Mead diz que sempre haverá uma resposta idêntica para um mesmo gesto, embora tenham origens em diferentes indivíduos. Todos compartiIham da mesma compreensão, da mesma experiência e a partir daí passam a incorporar em si mesmo tais comportamentos ${ }^{3}$.

O comportamento é sempre social e não uma resposta aos outros, porque o indivíduo responde tanto para si mesmo como para os outros e também responde da mesma forma que os outros lhe respondem. Quando isso acontece, a imaginação permite que o comportamento esteja sendo compartilhado com todos os outros pela conduta dos outros. Toda a ação é construída através da 'interpretação da situação' ${ }^{4}$ que está ocorrendo no momento. A vida em grupo consiste em unidades de ação que são desenvolvidas e 'incorporadas' para que novas ações e outras situações possam ser enfrentadas com interpretações nas quais todas elas já estão inseridas. Essa 'definições de situações' é um conceito que Mead tira de W. I. Thomas para explicar que sempre existe um estágio de exame e deliberação, onde o indivíduo, gradualmente adota uma política de vida e que também a personalidade segue dessas séries de tais definições de situações.

\section{3. 'Self' (personalidade)}

O fato de um indivíduo possuir o 'self' já Ihe credencia a agir socialmente com relação a outras pessoas e consigo mesmo. No entanto para que se possua tal 'self' é porque a vida acontece em sociedade. O 'self' torna-se objeto das próprias ações e objeto das ações dos outros. Ele é formado das 'definições' feitas por outros que servirão de referencial para que ele possa ver a si mesmo. O ser humano passa a ser objeto de suas próprias ações na sociedade (confirma assim que a sociedade precede o 'self'). A sociedade é o contexto onde o 'self' surge e se desenvolve. Passa de um estágio chamado de 'imitação', onde a criança não 'deposita' nenhum (não 'designa' ainda) significado nas coisas, para um estágio onde passa a 'assumir o papel dos outros', já com significados, até porque para assumir o papel do outro é preciso primeiro a capacidade de interpretação. Só nesse estágio é que surgem tais 'significados'. Quando a criança aprende a 'jogar com diferentes papéis', é porque ela já conseguiu construir o 'outro generalizado', pois pode internalizar as expectativas advindas dos outros e estabelecer associações. Cooley, um antecedente da 'teoria dos papéis', vai chamar esse processo de 'vidro refletido' ou 'olhando-se no espelho'.

Outros pesquisadores se interessaram pelo 'interacionismo simbólico'.

3 Questionamos aqui, inicialmente, embora nos tópicos seguintes far-se-á referências mais específicas, se não seria o mesmo que a 'mente incorporada' de Demo (2001), quando fala da aprendizagem; se não seria o mesmo que a 'incorporação' de Bracht (1997a), quando fala de pensamentomovimento; se não seria o mesmo que 'dimensão corporal sensível' de Hildebrandt-Stramann (2001), quando fala em reintegrar aos processos de experiência os momentos de experiências sensoriais, segundo o modelo da Gestalt.

4 Entendemos que a 'interpretação da situação' poderia estar no mesmo nível que a 'tipificação' de Schutz (apud Wagner, 1979). 
Meltzer e Petras (apud Haguette, 1987, p. $27 \mathrm{~s}$ ) buscam dados, tanto na Escola de Chicago (com Mead), como na Escola de lowa (com Blumer). Vão destacar semelhanças e distinções, e quando tratam das ideias de Mead sobre o 'self', distinguem duas fases analíticas distintas no processo social que acontece no interior do indivíduo:

a) $\mathrm{O}$ 'eu' é a tendência impulsiva do indivíduo. Ele é o aspecto inicial, espontâneo e desorganizado da experiência humana. Logo, ele representa as tendências não direcionais do indivíduo.

b) $\mathrm{O}$ ' $\mathrm{mim}^{\prime}$ representa o 'outro' incorporado ao indivíduo. Logo ele compreende o conjunto organizado de atitudes e definições, compreensões e expectativas - ou simplesmente sentidos - comuns ao grupo. Em qualquer situação o 'mim' compreende o outro generalizado e, raramente, o outro particular.

c) Todo ato começa na forma de um 'eu' e geralmente termina na forma de um 'mim'. Porque o 'eu' representa a iniciação do ato antes dele cair sob o controle das definições e expectativas dos outros (o Mim). O 'eu', pois, dá propulsão, enquanto o 'mim' dá direção ao ato. O comportamento humano, então, pode ser visto como uma série perpétua de iniciações de atos pelo 'eu' e de ações retroativas sobre o ato (isto é, direcionamento do ato) pelo 'mim'. O ato é a resultante desta interação.

Tanto o 'self' como o ato humano se originam socialmente, são dinâmicos, evoluem e se modificam de acordo com as mudanças dos padrões e dos conteúdos das interações. Isso acontece pelas experiências dos indivíduos consigo mesmo e com os outros. Só com o surgimento do 'self' é que o indivíduo passa a ter uma vida mental, podendo fazer indicações para si mesmo, dirigindo e controlando seu comportamento em vez de estar sendo guiado pelos impulsos e estímulos (conforme prevê o behaviorismo - psicologia comportamentalista).

\subsection{Mente}

O sistema nervoso central e o córtex cerebral fazem parte de um aparato fisiológico que Mead afirma ser indispensável para o organismo e para o desenvolvimento do ser humano. É através desse aparato e o respectivo desenvolvimento dos processos sociais de experiência que surge a gênese da mente, ou seja, é a partir de uma matriz de relações sociais e interações. O cérebro é necessário, mas sozinho ele não faz a mente, porque ela se constrói na sociedade-interação social, pois o comportamento humano inteligente é de origem social. Como diz Troyer (apud Haguette, 1987),

o self só poder surgir numa sociedade em comunicação. Assim também a mente só pode surgir num 'self' dentro da qual esta conversação de atitudes ou participação social toma lugar. É esta interação simbólica interposta pelo ato que constitui a mente.

Para Mead, 'a mente é concebida como um processo que se manifesta sempre que o indivíduo interage consigo mesmo usando símbolos significantes'. Assim, tanto a origem como a função da mente é social, pois surge de um processo social de comunicação. Por meio de um estímulo, todo e qualquer comportamento implica em uma percepção seletiva de situações. A mente possibilita que o indivíduo faça planos para atuar e lhe fornece sentidos. Esses funcionam como uma imagem padrão de ação e que vai definir o objeto ou o evento. Esta imagem padrão vai depender das experiências e das comunicações realizadas 
consigo mesmo e com os outros, pois elas são proporcionadas pela forma como os outros 'me vêem'.

\section{Mead e a Educação Física escolar: o 'outro generalizado' - do jogo ao esporte}

Vamos utilizar um texto de Mead (1986, trad. da edição em espanhol de $1972)^{5}$, que foi traduzido e adaptado pelo Grupo de Trabalho Pedagógico UFSM/UFPE (1991), durante os estudos de mestrado na UFSM, no período de 85/88. É um texto que trata da diferenciação entre o jogo e esporte, e é nesse processo de construção da diferenciação que vai surgir o clareamento da mais importante das categorias de Mead: o 'outro generalizado'.

Vamos começar com a distinção que nosso autor em questão faz do jogo e do esporte acompanhando o desenvolvimento da criança. Nas primeiras fases da criança percebemos determinadas características do jogo que são semelhantes aos jogos dos povos primitivos em cerimônias religiosas. Há que fazer algumas ressalvas em função de que a 'atitude lúdica pura' das crianças é diferente dos jogos praticados pelos adultos primitivos. Esses já possuem condições de interpretação de significados e esses podem estar incluídos no 'espírito' desses povos, fazendo parte dos rituais dos jogos.

Para Mead, esses rituais consistem em processos de organização dos jogos tais quais, quem sabe, àqueles que acontecem no jardim de infância - hoje, educação infantil, de zero aos cinco anos de idade
- quando as crianças jogam/brincam. Elas se reúnem em equipes que por si só já se apresentam com uma estrutura ou seleção definida. A descoberta do processo de organização bem como a prévia estrutura já definida é uma descoberta realizada através da pesquisa em jogos dos povos primitivos.

Essa 'prévia estrutura já definida' é uma classe de atividade diferente daquelas do cotidiano. No ritual, a natureza da atitude é vaga e incerta, com uma reação muito mais primitiva. A reação provocada encontra espaço na adoção do papel do 'outro' como deuses e heróis. É como se estivessem repetindo as expressões dos ditos deuses e heróis. Por outro lado, as crianças, quando jogam seus 'papéis', estariam fazendo a mesma coisa que os primitivos. Elas assumem papéis como sendo pais, professores, amigos e outros.

Essa 'imitação' é desenvolvida com uma personalidade vaga de quem está por perto, Ihe dá afeto e de quem elas dependem muito. Essas são as personalidades que adotam os papéis e que podem ser percebidas num jardim de infância com crianças brincando. O jardim organiza todos esses seres vagos e coloca-os numa relação social organizada. A aceitação dessa determinação da organização vinda de fora, confirma a falta de organização interior nesse período de desenvolvimento da criança.

A diferença entre jogo e esporte, para Mead, é que para o esporte, a criança necessita ter condições de assumir a atitude de todos os 'outros' que estão envolvidos no jogo. Essa é a capacidade exigida das atitudes dos que estão envolvidos no mesmo pro-

5 Aliás, pouco conhecido no interior das reflexões sobre jogo, esporte e Educação Física escolar no Brasil. 
cesso. Essa comunidade ou grupo, ou equipe passa a ser chamada de 'outro generalizado'. Qualquer atitude do 'outro generalizado' é a atitude de toda a comunidade, de toda a equipe coletivamente. Por isso o esporte faz surgir e exige a personalidade organizada.

A criança, quando pratica esporte, alcança um 'outro organizado', que se acha na natureza mesma da criança, e encontra sua expressão na experiência imediata deles. Tanto que é a atividade organizada da natureza psíquica da criança que the proporciona unidade e lhe constrói socialmente como pessoa. Continua o autor dizendo que a criança passa do jogo para o esporte 'naturalmente', e dele tem de participar, porque a moral do esporte se apodera da criança com maior força do que a moral mais ampla da comunidade. Também a moral do esporte Ihe oferece maior atração, mais do que a moral da família à qual pertence, ou da própria comunidade em que vive. ${ }^{6}$

Já para o jogo, a criança simplesmente vive seus próprios personagens interiores, suas fantasias. As normas e regras do jogo são criadas e modificadas por ela mesma. Não existe aí nenhum 'outro generalizado', até porque a criança ainda não atingiu mentalmente essa capacidade de interpretação do papel do 'outro'. Ela simplesmente vai assumindo sucessivamente (um atrás do outro) os papéis que fazem parte de suas fantasias. Essa é a característica da criança. Num momento ela é um papel e em outro momento ela já é outra e muito menos vamos poder sequer imaginar o que ela será a seguir. Esse é o encanto e a imperfeição da infância. Ela não está ainda organizada como um todo e não tem nem caráter e nem personalidade definidos. Vai chegar um momento em que essa interpretação vai ser possível, ela terá o 'self' desenvolvido e aí então poderá participar do esporte, como uma organização mais complexa, até porque ela já terá criado socialmente essa organização complexa também no seu interior, psiquicamente.

A criança, a partir dessas características, poderá participar da sociedade e se desenvolver como pessoa no sentido mais amplo, no entanto não é só com essa capacidade de ter consciência de si e ter consciência do 'outro generalizado', ou seja, deles entre si. Será necessário que o indivíduo incorpore esse processo social como um todo à sua experiência individual. Como diz Mead (1986, p. 3s - trad. da edição em espanhol de 1972 pelo GTP),

essa incorporação das atividades amplas de qualquer 'todo social dado' ou sociedade organizada, ao campo experimental de qualquer dos indivíduos envolvidos ou incluídos nesse todo é, em outras palavras, a base essencial e

6 Ver em Douglas (1984) o capítulo 13, Desenvolvimento moral, do livro A criança em desenvolvimento, onde a autora apresenta três subsistemas de desenvolvimento moral: a) comportamento moral; b) sentimentos morais; e c) julgamento moral. Mais adiante a autora apresenta num quadro os seis passos, divididos em três níveis básicos previstos por Kohlberg, que vão além daqueles previstos por Piaget, pois a Kohlberg interessa o tipo de raciocínio que a criança usa para lidar com os problemas cotidianos. Kohlberg concebe a possibilidade de introdução de sistemas de raciocínio moral nas escolas e com isso elevar o nível de compreensão moral das crianças através de 'treinamentos específicos'. Julgamos conveniente essa nota, pois tanto os jogos como o esporte compõem o sistema de ensino nas escolas. Seria, então, mais adequado e mais 'fácil' que os professores de Educação Física contribuíssem pedagogicamente nessa responsabilidade, tanto a nível social como individual. 
pré-requisito para o pleno desenvolvimento da pessoa desse indivíduo.

O conteúdo do 'outro', que penetra em uma personalidade, é a reação, no indivíduo, que seu gesto provoca no outro. Tanto que uma pessoa é uma personalidade porque pertence a uma comunidade, porque incorpora as instituições de dita comunidade à sua própria conduta. Esse pertencimento à comunidade ainda vai necessitar da linguagem como meio fundamental para conseguir a construção da personalidade. $\mathrm{E}$ em seguida, com a capacidade de assumir os distintos papéis proporcionados por todos os membros da comunidade, o indivíduo alcança a atitude que lhe confere ser membro de uma comunidade, ou seja, já possui a estrutura da personalidade de um homem/mulher.

\section{Compreendendo a formação do 'self': caminhos e perspectivas na educação das crianças}

$\mathrm{Na}$ construção da teoria da personalidade, em busca da individuação, Mead fundamenta o 'outro generalizado', que é perceptível inclusive com exemplos específicos na área do jogo e do esporte, ou seja, tão próximos do nosso campo de intervenção, o que facilita a compreensão. Nossa formação profissional poderia contemplar tal distinção, onde a construção da mente e a construção da sociedade implicam em tornarem-se um processo dialético, antes mediatizado pela personalidade (pelo 'self').

A teoria da personalidade permite a compreensão do desenvolvimento dos símbolos significantes (aqueles que constroem a rede de interpretações significativas) pelo sujeito, e fornece elementos para a fundamentação do indivíduo com condições de agir socialmente (tanto consigo como com os outros).

Quando a criança se encontra na fase da 'imitação' ela não vê nenhum significado nas outras 'coisas'. Em seguida, ela passa a assumir determinados papéis, não por imitação, mas sim por interpretação. É o surgimento dos significados que antes ela não conseguia 'ver' (ou melhor, interpretar). Nesse 'jogo' com outras interpretações, a criança constrói sua personalidade e consequentemente surge o 'outro generalizado'. Consegue relacionar-se consigo e com os outros, estabelecendo relações psicossociais.

Em todo momento se reconstrói novos significados. Isso não tem mais fim e é nessa infinitude comunicativa (de gestos) que Mead colabora com Habermas na recuperação do sujeito e da compreensão necessárias à emancipação individual e social.

A criança quando joga, dentro da dimensão lúdica, é difícil de fazermos alguma previsão, tanto na direção que o jogo vai tomar como no novo personagem que ela vai assumir para dar novo destino. Essa atividade lúdica ainda é desenvolvida com forças 'primitivas' pouco conhecidas, tanto pelo seu conteúdo como pela maneira como se expressa. A criança se apropria do momento de sua fase de desenvolvimento, segundo Mead, para 'canalizar' tais forças primitivas. Quando se aproxima o momento para uma fase seguinte, essas forças vão ganhando outro contorno. A ludicidade começa a perder espaço e surgem gradativamente algumas pequenas normas.

Em outro momento, já vão surgir regras e convenções, até que num determinado momento o jogo passa a ser aquilo que nós conhecemos por esporte - regras, normas e convenções rígidas. A criança já tem 
capacidade de interpretar as forças que agora vêm como reação ao seu comportamento significativo, partindo do 'outro'. Esse outro é aquele 'mim' que é resultado de sua própria construção e o 'mim' dos outros. O outro também utiliza o seu 'mim' para entrar em comunicação com outros 'mim'. Aqui está o 'nós', que em espanhol se diz 'nosotros'.

No esporte escolar é possível se reconstruir significações porque todos os integrantes conhecem e se reconhecem como 'nós'/'nosotros'. Qualquer atividade a ser desenvolvida é possível de ser interpretada significativamente. Pode não ser a mais 'adequada' para uns, no entanto é compreensível por todos. Tanto dialogicamente como didaticamente é possível construir a responsabilidade, o respeito mútuo, a cooperação e a competência coletiva. Mesmo que o esporte represente o aumento da complexidade de movimento dos homens, os processos de ensino e de aprendizagem que se utilizam do esporte devem reduzir essa complexidade, transformando esses elementos em circunstâncias significativas, através de um processo de ensino que 'abre' e 'fecha'. Mas o ensino só pode fazer isso porque ele se propõe 'aberto'. Consideramos que estando fechado, permite a dominação da irracionalidade, da mecanização e da dominação automática. Estando em aberto, resgata a compreensão e a possibilidade de reinterpretação, ganhando novos significados.

\section{Mead e a Educação Física escolar brasileira}

\subsection{Concepção de 'Aulas abertas às experiências'}

Já mencionamos em outra oportunidade as contribuições que o Grupo de
Trabalho Pedagógico UFPE/UFSM (1991) tem deixado para o arranjo de aulas de Educação Física. A partir das ideias de Mead, o Grupo fornece alguns princípios para que os integrantes do processo educativo percebam como determinadas organizações da aula têm íntima relação com o jogo e o esporte e que muitas vezes não são refletidas didaticamente.

Mead diz que a organização psíquica funciona de acordo com a organização do esporte como conhecemos hoje. Essa passagem automática do significado esportivo para o interior das aulas provoca o que o Grupo chama de 'congelamento das interações'. Por isso que só é possível 'descongelar' tais arranjos e encenações didáticas quando um novo processo de interação for construído, já agora por meio de novas interpretações sobre o significado dos movimentos e atividades da aula.

Essa interação simbólica permitirá a formulação de questionamentos pedagógicos e construção de novos espaços, com outras definições e determinações da aula. Para isso o Grupo apresenta além de reflexão teórico-crítica, exemplos práticos de várias aulas, nos mais diversos níveis de ensino.

\subsection{Concepção 'crítico-emancipatória'}

O trabalho do professor Kunz (1991), já conhecido no interior do campo da Educação Física escolar, faz referências às ideias de Mead, quando se compromete a oferecer à comunidade acadêmica uma nova concepção para o conceito de equilíbrio entre identidade pessoal e identidade social. Outra fonte é a concepção de educação do educador Paulo Freire, que se 
propõem transformadora, de acordo com as mudanças previstas também em nossa área. É a partir dessas contribuições que Kunz fundamenta sua didática-comunicativa.

Para o autor é necessário que se desenvolvam processos de interação onde os participantes se sintam sujeitos e que entrem em comum acordo para coordenar e sincronizar tais ações. Essa coordenação só é possível através de uma 'competência interpessoal'. Para Kunz (apud Mollenhauer, apoiado em Mead, 1991), diz que esta competência só surge quando o educando for encarado como um parceiro nas interações. Passa a se constituir em um 'sujeito-interacional' que consegue se organizar (individualmente) e organizar as ações internas dos 'outros' (coletivamente), através das experiências. Portanto, esse equilíbrio entre o individual e o coletivo (social) também é possível acontecer no interior das aulas de Educação Física.

\subsection{Concepção 'crítico-superadora'}

Outro trabalho acadêmico que faz citações de Mead é de Bracht (1997b). Sua Sociologia crítica do esporte coloca a nossa realidade esportiva em sintonia com o contexto mundial por um caminho que Ihe é característico. Por ter realizado seu doutoramento na Alemanha, teve acesso a estudos criteriosos sobre a sociologia crítica alemã. Isso Ihe proporcionou os aprofundamentos teóricos necessários para a análise crítica da realidade. Essa crítica de orientação frankfurteana lhe permite trafegar por temáticas como:
a) o esporte e a intersubjetividade;
b) o esporte e as instituições;
c) o esporte e a reprodução cultural; e ainda
d) o esporte e o marxismo ortodoxo.

Assim Bracht vai destacando que

a) Habermas se aproxima de Mead através da possibilidade de reconstrução do 'eu';

b) Bourdieu tem aproximações com as ideias de Goffman e da teoria do 'interacionismo simbólico', na tentativa de reintroduzir o ator no centro de suas análises, aproximando indivíduo e sociedade;

c) Berger \& Lückmann aproximam-se de Mead através do conceito 'assumir os papéis sociais do outro'.

Diante de tudo isso, Bracht faz um 'apanhado' criterioso dessas colaborações, e fundamenta sua sociologia crítica do esporte, aproximando todas essas abordagens, no sentido de tentar perceber o poder emancipatório contido nelas.

\section{Considerações sugestivas nas concepções 'críticas' de ensino}

Chegando ao final, mas não ao final da investigação temática, destacamos alguns aspectos psicossociais necessários, fazendo a ligação entre as concepções de ensino citadas anteriormente. Por outro lado, vamos destacar alguns elementos da relação didático-pedagógica das experiências da cultura de movimento como 'aprendizagem', pois conhecer como acontecem os processos de ensino e de aprendizagem é fundamental e necessário nas concepções didáticas em questão.

\subsection{Grupo Trabalho Pedagógico UFSM/ UFPE, Hildebrandt(-Stramann)}

Quando Hildebrandt (1993) trata da questão da experiência como categoria central da 'concepção de aulas abertas às 
experiências', vai destacar a relevância didática de como um processo dialético, tanto da constituição do momento em que ela ocorre como da aquisição da experiência em si.

a) Quanto à constituição do momento em que ocorre a experiência, o autor se refere ao 'mundo da vida' como sendo o local ideal para tal ocorrência; e

b) Já quanto à maneira pela qual se adquire a experiência, interessa a forma como se configura a aula de Educação Física.

Hildebrandt se preocupa com o aumento da desvalorização da experiência cotidiana, que está sendo substituída pela experiência científica e assim ampliando a cientifização do 'mundo vivido'. Apesar dessa incontestável realidade, a experiência, para o autor, é aquela que ocorre no mundo da vida, que nós percebemos através dos sentidos e que está ligada diretamente ao corpo.

Tanto Merleau-Ponty como os gestaltistas investigaram a capacidade humana da percepção, da orientação e da aprendizagem. A experiência do mundo da vida é uma experiência cinestésica que abre a estrutura das coisas e que não necessita de condições objetivas de controle. O que importa é a experiência individual ${ }^{7}$, que Hildebrandt (1993), ao apoiar-se em Hegel, diz que 'o homem tem que ficar presente, presente com seu corpo integralmente'.

Dessa forma é que ocorrem, subjetivamente, as experiências individuais. Cada experiência tem sua história, assim como cada indivíduo possui sua 'encarnação biográfica'. É a partir delas que se definem outras possibilidades de experiências dentro daquelas que já possuímos em nosso interior. $\mathrm{O}$ acesso ao conhecimento e o 'acúmulo de saberes' dependem dessas experiências que já realizamos e daquelas que vamos realizar no curso contínuo das 'tipificações'.

O autor transporta essa categoria da experiência (que acontece dentro do mundo da vida) para o interior da Educação Física escolar e pergunta pelas consequências das experiências que estão sendo desenvolvidas.

a) Em primeiro lugar ele vai dizer que as experiências que até agora têm acontecido, são aquelas com íntima ligação com experiências laboratoriais. As experiências são comparadas. Os sujeitos são comparados objetivamente diante de suas experiências, por desempenho, por rendimento e por produção.

b) Em segundo lugar, é preciso entender que esse tipo de procedimento torna o sujeito 'impotente' diante da possibilidade de construir, inclusive sua própria identidade, o que acarreta um 'peso' para reconstruir experiências como aquelas já interiorizadas no mesmo curso das 'encarnadas biograficamente no mundo da vida'.

Nossa entrada (emergência) no mundo se dá pela via corporal e não pela via intelectual. Mead confirma essa tese dizendo que a mente se constrói após a construção social da personalidade. Mas por outro lado, Hildebrandt diz que o 'nosso conhecer tem de ser ligado com as coisas do mundo, com as coisas fora do corpo'. Essa ligação do exterior com o interior ${ }^{8}$ se dá pela via da experiência corporal e sensível.

7 Tal como ocorre na tipificação - uma experiência única para a construção da identidade.

8 Ver Santin (1996, p. 61), no exemplo do iogui em um exercício corporal [ritual], retirado da obra 'O corpo em Discussão', de Jean Le Camus. 
Mais adiante Hildebrandt (1993) busca auxílio em Piaget para mostrar que esse processo tem validade em dois processos de experiência: tanto na acomodação como na assimilação. Nessa transição entre uma e outra, o sujeito ganha experiências para a construção de sua identidade e conhecimento sobre si mesmo. Se o conhecer começa pela experiência, é porque temos aí o aparecimento e a inclusão da categoria corporal-sensível. Nenhuma experiência científica substitui esse acontecimento do mundo da vida.

Para Hildebrandt-Stramann (2001), quando a Educação Física não consegue proporcionar essas experiências na dimensão corporal-sensível é porque ela está muito afastada do mundo da vida e mais próxima da cientifização da realidade. Tornam os sujeitos impotentes diante das possibilidades de movimento, adaptando-os ao sistema esportivo de rendimento, com tarefas esportivo-motoras estereotipadas.

Na continuidade desse debate, e defendendo a concepção de 'aulas abertas às experiências', o autor vai apresentar dois pontos de vista utilizados no interior dessa prática pedagógica:

a) O primeiro é de que os alunos devem ter a liberdade para que possam atuar autonomamente. Essa individualidade vai permitir um 'saber' e um 'conhecer' construído cognitivamente consigo mesmo, e, ao mesmo tempo, com os 'outros'. Esse processo autônomo não poderá ser substituído por qualquer outro de caráter informativo ou técnico, pois estaria negando a experiência individual na construção da identidade própria. b) O segundo ponto de vista é quanto à oferta de possibilidades para que os alunos atuem autonomamente, permitindo que eles façam suas próprias interpretações significativas sobre o movimento em questão. Essa é a verdadeira busca, a procura individual que é insubstituível e denominada pela antropologia pedagógica de Roth, como na teoria da gestalt, com o nome de 'liberdade criativa'.

Esse segundo ponto de vista é um movimento que tem o aspecto 'vivo' como sua característica principal e exige a participação consciente do sujeito. Essa é a forma como as 'aulas abertas às experiências' encaram o processo de ensino e de aprendizagem. Um conhecimento produzido pela experiência individual (em forma de aprendizagem 'incorporada'), numa ação conjunta com 'outros' integrantes, que também trabalham no mesmo percurso ${ }^{9}$.

\subsection{Kunz e a didática comunicativa}

Num artigo que trata de 'Uma abordagem fenomenológica do esporte', Kunz (2000) aponta para três aspectos que integram o esporte, mas que só são percebidos quando abordados fenomenologicamente, a saber: a percepção, a sensibilidade e a intuição no esporte. Vamos ver cada uma delas e quais suas relações e quais os elementos comuns com a questão da aprendizagem. Mesmo porque cada um desses aspectos é parte integrante de qualquer tipo de movimento (ou gesto/conduta técnica) e são também decisivos quando da execução desses respectivos movimentos. Kunz exemplifica

9 Onde interiormente não há medida, mas quando expressadas exteriormente, apresentam diferenças corporalsensíveis. 
... a sensibilidade na forma como a bola 'cola' no pé do jogador de futebol; a percepção de tempo e espaço e seus respectivos modos e maneiras diferentes que interpretamos as grandezas físicas e mensuráveis de um jogo coletivo; e a intuição no exemplo de 'ver' antecipadamente, tanto com êxito como com fracasso, um determinado lance de jogo.

Visto assim, ele se refere aos gestos esportivos somente de forma analítica, até porque quando da execução não é possível separar a sensibilidade da intuição e muito menos a intuição da percepção e assim por diante. O Ser e Agir Humanos, vistos através da abordagem fenomenológica, não podem cair no 'intelectualismo', ato tão comum entre os profissionais da área, estudantes e atletas.

$\mathrm{Na}$ fenomenologia, o que interessa é chegar ao 'conhecimento do conhecimento'. Se não for assim, pode-se cair no psicologismo e Husserl provocou a criação da categoria da intencionalidade e esclareceu o fato de que 'consciência é sempre consciência de alguma coisa', ou seja, é uma intencionalidade que nos move. Tal intencionalidade se exterioriza, é conhecida pelo 'mim' e a partir daí os 'outros' passam a conhecer as intenções do 'eu' como um objeto, uma coisa. Também como um veículo, a intencionalidade vincula o mundo (o exterior, os personagens, o 'outro generalizado', o tempo cósmico) com a consciência (o tempo interior, a durée - a duração, o eu-identidade, o momento da tipificação).

$\mathrm{A}$ intencionalidade não pertence nem ao sujeito nem ao objeto. Ela transita, ela transpassa, faz a passagem entre as duas dimensões do tempo e do espaço (interior e exterior). Husserl vai chamar esse momento de 'vínculo profundo' de 'original', porque é nesse momento que nossas experiências, vivências e o modo de pensar 'constituem' o objeto de conhecimento na consciência.
Assim surgem as 'aparências originais' e nos relacionamos com os objetos através da experimentação, das vivências e do conhecer. Papel esse desempenhado pelo 'mim' ou melhor, pelo 'outro generalizado' de Mead e que Merleau-Ponty diz que se inicia sempre 'corporalmente'.

É por isso que a fenomenologia percebe as coisas quando 'descreve' e não quando 'analisa'. As experiências se transformam num horizonte de possibilidades, ou como diz Gadamer (2004 e 1977), na 'fusão de horizontes'. As experiências provocam uma forma de 'ver' a realidade e a vida individual; a encarnação biográfica e a tipificação dão início a essa reflexão sobre 'si mesmo'. Cria o 'mim', que é parte do 'eu' como uma unidade e assim se comunica com os outros através da rede significações e intencionalidades.

Com a fenomenologia é possível investigar esse 'campo aberto de significações'. Temos aí diante de nós a chance de reinterpretar as significações dadas pelo 'mim' através das provocações e reações intencionais originadas no 'eu', mas controladas e modificadas pelo ' $\mathrm{mim}$ '.

Os três aspectos esportivo-fenomenológicos destacados por Kunz (2000) anteriormente, podem ser conhecidos através de operações mentais, ou seja, pelo conhecimento discursivo mediado pelas operações racionais. No entanto, o autor aponta para a possibilidade de outro tipo de conhecimento, intuitivo, que

a) é imediatamente apreendido e de natureza 'corporal-sensível'. Tal conhecimento se manifesta em forma de um 'saber' anterior à própria ocorrência de algo, evento que mais acontece no interior do jogo esportivo.

b) também indica a intuição formal-sensível que fornece base para o intelecto 
('a mente', como já vimos anteriormente, é algo que se alcança posteriormente à personalidade. Com a personalidade sendo construída, a criança terá capacidade mental, identidade que possibilita interpretar significações com outros sujeitos). c) e por fim, apresenta também a 'intuição supra-sensível', de registros na consciência de dados imediatos que podem ou não ser confirmados a posteriori ${ }^{10}$.

Essas duas últimas formas de intuição acontecem e se desenvolvem na dimensão corporal, ou seja, na corporeidade e o mundo não é aquilo que nós pensamos, mas sim aquilo que vivemos. Nossas experiências no mundo da vida se tornam o momento de intervenção, da aprendizagem corporal-sensível.

$\mathrm{O}$ autor finaliza seu texto dizendo que essa abordagem tem servido para que se possa 'jogar mais luz sobre o esporte através da fenomenologia', no entanto talvez fosse possível 'conseguir jogar mais luz sobre a fenomenologia através do esporte'. Dessa forma também podemos fazer uma analogia com o pensamento e obra de Mead, quando ele esclarece a categoria do 'outro generalizado' por meio do jogo e do esporte, ou seja, o autor joga mais luz sobre a categoria do 'outro generalizado' por meio do esporte e do jogo.

\section{CONSIDERAÇÕES (SEM-I)FINAIS}

Tendo aproximado uma das categorias mais importantes, denominada 'corporal-sensível', entre as concepções do 'movimento renovador' da Educação Física escolar (Bracht (1999a), indicamos algumas sugestões da investigação:

1) A Psicologia Social de Mead sofre um vácuo provocado pela não divulgação fora do território norte-americano, tornando-a desconhecida na Europa e, por ficar de fora das reflexões da época, afasta-se das diversas possibilidades de acesso às várias teorias psicossociológicas no último século;

2) A Psicologia Social ('condutismo social') surge para confrontar a Psicologia Comportamentalista (behaviorismo), de característica eminentemente norte-americana e aquela não teve a devida repercussão científica mundial quanto essa;

3) A Psicologia Social, que justamente trata da relação dialética indivíduo-sociedade, que no nosso entender proporcionou a 'guinada' na psicologia com a teoria dos 'papéis recíprocos', passou ao largo durante esse tempo, aprofundando mais ainda os obstáculos nas 'imprescindíveis e necessárias' intervenções didático-pedagógicas na Educação Física escolar;

$\mathrm{Na}$ atual sociedade do conhecimento, a educação passa a ter um papel fundamental. Demo (2001) faz algumas indicações, mas ressalta para o seguinte quando se trata da relação entre conhecimento e educação: esta necessidade precisa ser vista em ambas as direções, da educação para o conhecimento e do conhecimento para a educação.

Assim o papel da escola é coordenar esse confronto com a pobreza política em que nos encontramos. Aprender a ler não é só 'ler' a palavra, mas também estabelecer um diálogo com o mundo. O 'se-movimentar' é uma categoria que permite essa 'leitura'.

10 Esses registros ocorrem no tempo interior, na durée, ficam ali disponíveis, até porque essa dimensão de tempo possui outra dinâmica, diferente daquela do mundo exterior, do tempo cósmico. Só o 'eu profundo' individual é quem conhece essa região; ver sobre esse tema Bergson (1989) e Trevisan (1995). 
O indivíduo, a partir de sua condição no processo educativo, constitui-se em um possível cidadão crítico e criativo para aprender o saber pensar e intervir na realidade. Eis algumas possibilidades:

a) a 'liberdade criativa', indicada por Hildebrandt-Stramann (2001);

b) o conhecimento intuitivo apreendido através da natureza 'corporal-sensível' corporeidade, indicada por Kunz (2000); c) a 'epistemologia do movimento' que ocorre durante o 'se-movimentar', em forma de uma 'incorporação', que Bracht (1997a) vai chamar de 'movimentopensamento'; e

d) por último, na esteira de ideia de sistemas autorreferenciados, de Maturana e Varela (apud Demo, 2001) nos apresenta a categoria 'enação', onde a própria 'reflexão', agora 'corporificada', já se torna uma 'experiência', porque somos sujeitos capazes de 'auto-interpretação' e de 'auto-entendimento'.

As intenções das propostas didático-pedagógicas da Educação Física escolar, chamadas 'críticas', apontam para a direção de uma abordagem de intervenção 'criativa' e não técnico-racional. Isso leva Bracht (1999b) a fazer algumas proposições, entre elas, aquela de que ele chama de intervenção 'autopoiética', construída a partir de dentro da Educação Física. O resultado não pode ser uma teoria que substitua a prática, e vice-versa, mas que tenha lógica e que ambas precisam fecundar-se mutuamente, de modo que cheguemos numa teoria da prática e numa prática teorizada.

Das propostas alternativas hoje presentes no interior da Educação Física, a que mais tem Ihe demonstrado afinidades 'psíquicas' e epistemológicas se encontram naquelas que também se propõem a teorizar sobre a prática humana e consequentemente sobre a prática pedagógica. A investigação é no sentido de perceber e indicar se há uma nova ciência a caminho e se o seu objeto de estudo existe cientificamente.

No entanto, o autor ressalta que a tarefa é difícil, mas não impossível, porque o esporte apresenta algumas dificuldades para o desenvolvimento de uma prática pedagógica crítica, mas mesmo em condições, digamos de 'desvantagem' no placar, o esforço continua porque também acreditamos na necessidade de um projeto não só didático-pedagógico, mas também político-pedagógico.

Nessa mesma linha de intervenções e pesquisas, Kunz (1999) constata que a grande maioria das experiências desenvolvidas, que poderiam estar colaborando no avanço dessas questões, sobre emancipação teórico-prática, submetem-se ao uso e manuseio de um instrumental metodológico que vem cercear as perspectivas críticas e as novas reinterpretações significativas.

Diante dessas observações, entendemos que o caminho estará sempre nessa relação crítico-hermenêutica e crítico-dialética, pois é o motor para a construção daquilo que acreditamos ser um mundo mais sensato, cooperativo, responsável e congruente, tanto na dimensão social como individual. Ao desejar isso, o 'outro generalizado' também vai se sentir provocado. Não estaria assim formada a rede ilimitada de comunicação? ${ }^{11}$.

11 p.s.: Esse comentário em forma indagativa, foi feito por Valter Bracht e só sei dizer que ele tem uma 'amplitude' do tamanho 'do mundo'. Convoca a 'todos' indistintamente, mesmo sabendo que ali ele estava a 'cutucar' os próximos da Educação Física escolar. 


\section{REFERÊNCIAS}

BERGSON, H. Vida e obra. In: Cartas, conferências e outros escritos. Trad. Franklin L. e Silva. São Paulo: Nova Cultural, 1989, p. 113-9 (Coleção Os Pensadores).

BRACHT, V. A constituição das teorias pedagógicas da educação física. Cadernos CEDES, ano XIX, n. 48, agosto/1999a.

. Educação Física e ciência: cenas de um casamento (in)feliz. ljuí: EdUnijuí, 1999b. [Col. Educação Física].

- Educação Física: conhecimento e especificidade. In: SOUZA, E.S. e VAGO, T.M. (Orgs.). Trilhas e partilhas: Educação Física na cultura escolar e nas práticas sociais. Belo Horizonte: EdUFMG, 1997a, p. 13-23.

. Sociologia crítica do esporte: uma introdução. Vitória: EdUFES, 1997b.

DEMO, P. Educação e conhecimento: relação necessária, insuficiente e controversa. 2 ed. Petrópolis: Vozes, 2001.

DOUGLAS, H. B. Desenvolvimento moral. In: A criança em desenvolvimento. 3 ed. Trad. Rosane A. Pereira. São Paulo: Harper \& Row do Brasil, 1984, p. 327-49.

GADAMER, H.-G. Verdade e método II: complementos e índice. Trad. Enio P. Giachini. 2 ed. Revisão da trad. Márcia S. C. Schubrack. Petrópolis: Vozes e Bragança Paulista: EdUSF, 2004. (Col. Pensamento Humano).

- Teoria, técnica, prática: A tarefa de uma nova Antropologia. Trad. Hanna A. Rotschild. In: Nova Antropologia: O homem em sua existência biológica, social e cultural. [Orgs. Gadamer, H.G. e Vogler, P.]. São Paulo: EPU, 1977, p. 1-19. (Col. Nova Antropologia, v. 1, Antropologia Biológica I).

GRUPO DE TRABALHO PEDAGÓGICO UFPE/UFSM (Cardoso, C. L. [Org.]). Visão didática da Educação Física: análises críticas e exemplos práticos de aulas. Rio de Janeiro: Livro Técnico, 1991. [Coleção, v. 11].

haGuette, T. M. F. Metodologias qualitativas na sociologia. Petrópolis: Vozes, 1987.

HILDEBRANDT-STRAMANN, R. Textos pedagógicos sobre o ensino da Educação Física. Ijuí: EdUnijuí, 2001.

HILDEBRANDT, R. Experiência: uma categoria central na teoria didática das aulas abertas. Revista Brasileira de Ciências do Esporte - CBCE, v. 14, n. 3, 1993, p. 140-5.

KUNZ, E. Esporte: uma abordagem com a fenomenologia. Movimento, Ano 6, n. 12, 2000. (N. Especial). . Esclarecimento e emancipação; pressupostos de uma teoria educacional crítica para a Educação Física. Revista Movimento, Ano 5, n. 10, 1999.

. Educação Física: ensino e mudanças. Ijuí: EdUnijuí, 1991. [Coleção Educação, v. 11].

MEAD, H. G. O jogo, o esporte e o 'outro' generalizado. Texto mimeografado, trad. e adaptado (edição em espanhol Espiritu, persona y sociedad, 1972) no Curso Mestrado em Educação Física - UFSM, pelo Grupo de Trabalho Pedagógico, disciplina Pedagogia do Esporte, Prof. Reiner Hildebrandt, I Semestre de 1986.

. Espiritu, persona y sociedad: desde el punto de vista del conductismo social. Intr. Charles W. Morris. Buenos Aires: Paidós, 1972. [Coleção Biblioteca de psicologia social y sociologia, v. 3]. 
SANTIN, S. A biomecânica entre a vida e a máquina: um acesso filosófico. ljuí: EdUnijuí, 1996.

TREVISAN, R. M. Bergson e a educação. Piracicaba: EdUnimep, 1995.

WAGNER, H. R. [Org.]. Alfred Schutz na Fenomenologia e relações sociais. Trad. Ângela Melin. Rio de Janeiro: Zahar,
1979. [Coleção Biblioteca de Ciências Sociais].

WERLE, D. L. Indivíduo e sociedade: Habermas e a psicologia social de Mead. Mente\&Cérebro. São Paulo: Duetto, v. 8, abril, 2008, p. 40-7. (Col. Fund. Filosofia no séc. XX - Formação do Indivíduo e Socialização).

GAME, SPORT, CHILD AND EDUCATION: approximations with the Social Psychology theory of Mead

\begin{abstract}
The article think about the game and the sport within the social psychology theory of the philosopher G. H. Mead in the field of Physical Education. Initially indicates the principles of 'social behaviourism' [society, person and mind]. Then shows the 'emergency' of the 'generalized other' in the transition from the game to the sport. Further highlights the 'renewal movement' of the 80s and some references of education in Brazil. Finally think about the need to understand the development of the self in school education, highlighting the "critical" concepts for the didactic education of teachers.
\end{abstract}

Key-words: Social Psychology; Physical Education; Game and Sports; Child and Self.

Recebido em: setembro/2013

Aprovado em: março/2014 